\title{
Pseudotelegeusis meloi sp. nov., the first Telegeusinae from Peru (Coleoptera: Omethidae, Telegeusinae)
}

\author{
André Silva ROZA ${ }^{1}$, Robert CONSTANTIN ${ }^{2} \&$ José Ricardo Miras MERMUDES $^{3}$ \\ ${ }^{1,3}$ Laboratório de Entomologia, Departamento de Zoologia, Instituto de Biologia, \\ Universidade Federal do Rio de Janeiro, A1-107, Bloco A, Av. Carlos Chagas Filho, \\ 373, Cidade Universitária, Ilha do Fundão, Rio de Janeiro, RJ, Brazil. \\ ${ }^{2} 103$ impasse de la Roquette, 50000 Saint-Lô, France. \\ ${ }^{1}$ Corresponding author: andreroza1993@gmail.com \\ 2Email: rconstantin50@gmail.com \\ 33Email: jrmermudes@gmail.com \\ ${ }^{1}$ urn:lsid:zoobank.org:author:19835428-69EF-4E14-8B8E-3AC644BC4984 \\ ${ }^{2}$ urn:1sid:zoobank.org:author:7050FD35-153E-4AF8-8593-EEE7871DEC3A \\ ${ }^{3}$ urn:lsid:zoobank.org:author:A8A8CF2F-7ED4-4FE1-BA4B-14EB43DA2D55
}

\begin{abstract}
Telegeusinae is a small subfamily of Elateroid beetles presently attached to the Omethidae family. Pseudotelegeusis Wittmer, 1976 is composed of three species, two occurring in northern South America and one in Mexico. Here we describe the fourth species for the genus, Pseudotelegeusis meloi sp. nov., collected in a Malaise sample from the region of Madre de Dios, Peru. The new species is diagnosed mainly by the antennae serrate from antennomeres III to X, eyes occupying half of head width in lateral view and vertex occupying $3 / 5$ of head in dorsal view. This new species is close to the other two South American species, P. howdeni Wittmer, 1976 and P. oculatus Wittmer, 1976, according to the serrate antennae and number of ventrites. The three South American species differ from the Mexican species, P.jiliotupaensis Zaragoza-Caballero, 2008, by the different antennae and the number of ventrites, which indicates that the Mexican species should possibly be classified in a different genus. The main morphological characters, including maxillar palpi, tentorial pits and male genitalia, are illustrated, and an updated key to the species of Pseudotelegeusis is given, as well as distribution maps.
\end{abstract}

Keywords. Amazon, long-lipped beetles, Malaise trap, neotropical, taxonomy.

Roza A.S., Constantin R. \& Mermudes J.R.M. 2019. Pseudotelegeusis meloi sp. nov., the first Telegeusinae from Peru (Coleoptera: Omethidae, Telegeusinae). European Journal of Taxonomy 553: 1-13. https://doi.org/10.5852/ejt.2019.580

\section{Introduction}

Telegeusinae is a small subfamily of rarely collected beetles, composed of 20 species in three genera (Fleenor \& Taber 2001; Ivie 2002; Zaragoza-Caballero 2015): Telegeusis Horn, 1895, with 16 species distributed from southern United States to Panama (Fleenor \& Taber 2001; Zaragoza-Caballero 2015); 
Pseudotelegeusis Wittmer, 1976, with three species from French Guiana, Trinidad and Tobago, Venezuela, Ecuador and Mexico (Wittmer 1976b; Zaragoza-Caballero 2008); and Pseudokarumia Pic, 1931, with one species from Costa Rica and Panama (Ivie 2002). The phylogenetic position of Telegeusinae is still debated within the Elateroidea superfamily, depending on the analysis (Branham \& Wenzel 2001, 2003; Bocakova et al. 2007; Hunt et al. 2007). Recent molecular studies point to a relation of the group with the Omethidae (Mckena et al. 2015; Bocak et al. 2018), as a subfamily within the group (Kundrata et al. 2014). Morphological basis for this relationship, however, were not found yet.

Pseudotelegeusis is represented by the following species: the type species, P. howdeni Wittmer, 1976 (French Guiana, Trinidad and Tobago, Venezuela), P. oculatus Wittmer, 1976 (Ecuador) and P.jiliotupaensis Zaragoza-Caballero, 2008 (Mexico). The genus is recognized by the strongly serrate antennae (except for P. jiliotupaensis); the maxillary palpi composed of four palpomeres, the last enlarged; labial palpi composed of one palpomere; and, according to the authors, only one single tentorial pit (Wittmer 1976b; Ivie 2002; Zaragoza-Caballero 2008). So far, the species were only recorded by their original description, except for P. howdeni, which was later recorded for French Guiana (Constantin 2010).

The Peruvian Amazon includes a large subcontinuous area of primary forest, and is considered a priority in terms of global biodiversity inventories (Brooks et al. 2006). The number of species listed from there is increasing every year (e.g. Gonçalves et al. 2014; Cavichioli \& Takiya 2012; Chaparro et al. 2007), but it is a race against deforestation, alas important (from 1999 to 2005, for example, around $650 \mathrm{~km}^{2}$ were lost annually according to Oliveira et al. 2007), with the reduction of the habitat of still-unknown species.

The goal of this study was to describe a new species of Pseudotelegeusis from the regions of Madre de Dios, Huánuco and Loreto, Peru, to give an account of its intra-specific variability, to provide a key to the species of the genus, and to discuss the family's distribution and its rarity in collections. Incidentally, we controlled the character of the tentorial pit and found the presence of two tentorial pits on the ventral face of the cephalic capsule.

\section{Material and Methods}

\section{Study area}

The region of Madre de Dios, Peru, includes around 15\% of the Peruvian Amazonian Rainforest, with altitudes from 186 to 3500 m (Portal Oficial del Gobierno Regional de Madre de Dios 2015). The first recognized specimen was collected next to the highway "Interoceanica sur", which is near the Bahuaja Sonene National Park (PNBS, acronym in Spanish) (Figs 1A-B, 3E). The PNBS protects a region of 1091.416 ha. It includes vegetation types such as humid forest, submontane humid forest and tropical humid savannah ("Pampas del Heath"). Its climate is constituted by wet and hot summers, reaching $38^{\circ} \mathrm{C}$, and cold dry winters, descending to $8^{\circ} \mathrm{C}$. The area has an annual precipitation of $2400 \mathrm{~mm}$ (SERNANP2018). The holotype was collected in the CICRA biological station, in the Madre de Dios region. Additional paratypes from Madre de Dios, Huanuco and Loreto regions came also from similar habitats of the Amazonian foothills of the eastern cordillera.

\section{Collections and identification}

The holotype was preserved in $70 \%$ alcohol, then mounted on card, and the paratype specimens were mounted on cards. The specimen deposited in the Universidade Federal do Paraná (DZPR) is preserved in $92 \%$ alcohol. Specimens were deposited at the following collections:

\footnotetext{
$\mathrm{BMNH}=$ Natural History Museum, London, UK

DZUP = Coleção Entomológica Pe. Jesus Santiago Moure, Universidade Federal do Paraná, Paraná, Brazil

KUNHM = Kansas University Natural History Museum, Lawrence, Kansas, USA
} 

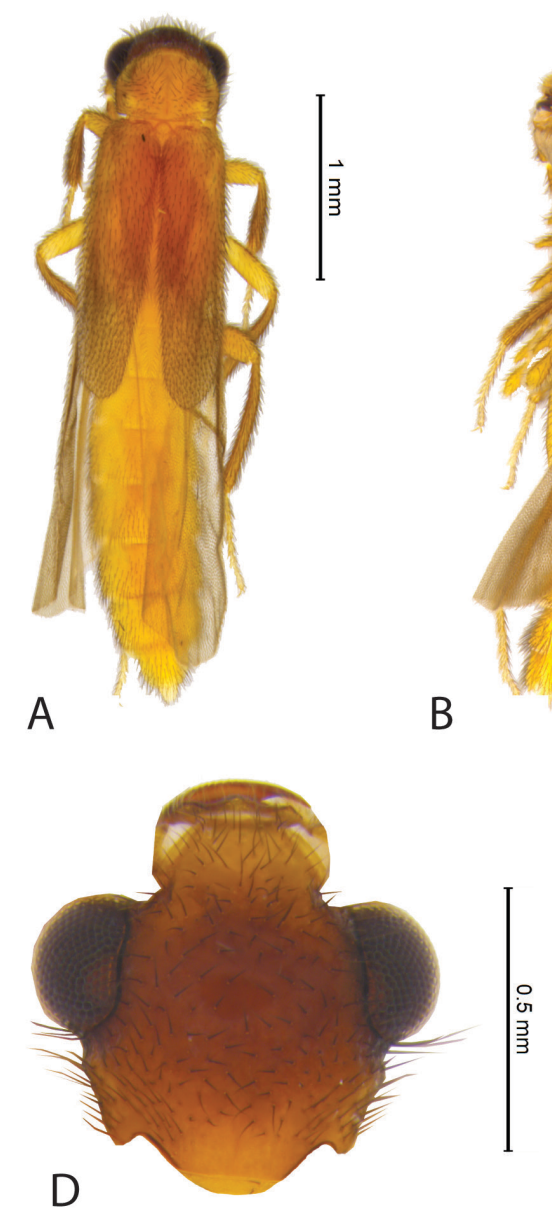
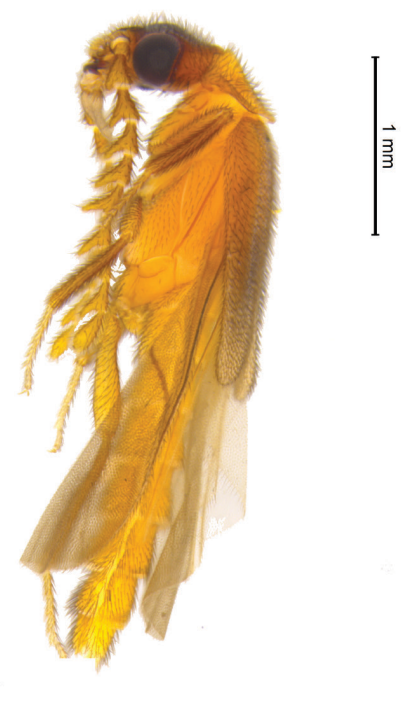

C

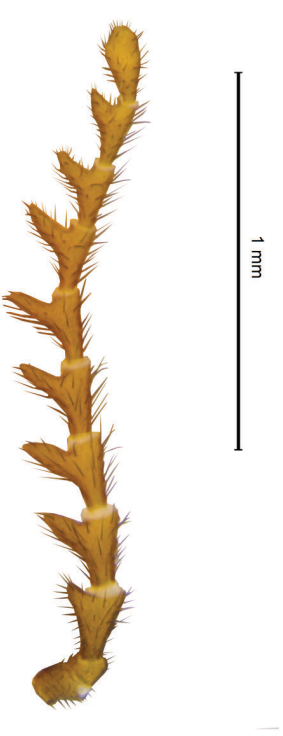

$\mathrm{E}$

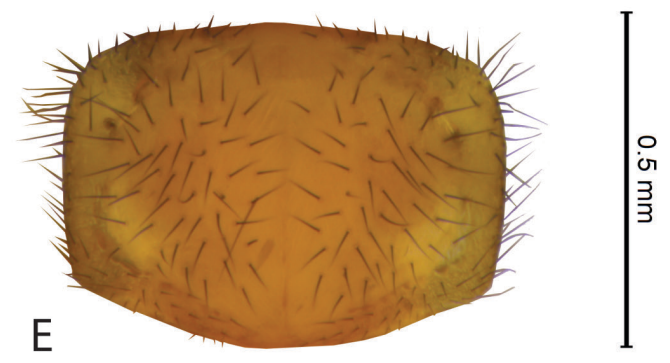

$1 \mathrm{~mm}$

$\mathrm{F}$

Fig. 1. Pseudotelegeusis meloi sp. nov., paratype from Mazuko DZUP 458.569. A. Habitus, dorsal view; B. Habitus, lateral view. C. Antenna, lateral view. D. Head, dorsal view. E. Pronotum, dorsal view. F. Left elytron, dorsal view. 


\section{Illustrations and dissections}

Photographs were taken partly under stereo microscope Leica DFC450 with the Application Suite CV3 multifocus software, partly with a DSLR adapted to a Leica MZ12.5 or to a Cambridge compound microscope, the frames fusion was realised with Helicon Focus Pro. The terminology follows Wittmer (1976b), Zagaroza-Caballero (2008) and Roza et al. (2017). Head capsule, last abdominal segments and genitalia were examined on holotype and paratypes after dissection and inclusion in a water soluble mounting medium. We generated the distributional maps using the software Quantum GIS 2.14.3 (QGIS Development Team 2016) and Data-Fauna-Flora 2017 (Mons University, Belgium).

\section{Abbreviations for measurement indices}

$\mathrm{AL}=$ antennal length, full extended

$\mathrm{EL}=$ elytron length from humerus to apex

$\mathrm{EW}=$ elytra combined width at the base

HW $=$ head width including the eyes

$\mathrm{IOW}=$ interocular width

$\mathrm{OL}=$ greatest length of the eye in lateral view

$\mathrm{PL}=$ pronotum length

$\mathrm{PW}=$ pronotum width

$\mathrm{TL}=$ total length

\section{Results}

Class Insecta Linnaeus, 1758

Order Coleoptera Linnaeus, 1758

Superfamily Elateroidea Leach, 1815

Family Omethidae LeConte, 1861

Subfamily Telegeusinae Leng, 1920

Genus Pseudotelegeusis Wittmer, 1976

Pseudotelegeusis Wittmer, 1976: 293

Pseudotelegeusis - Zaragoza-Caballero, 2008: 369

Key to species of Pseudotelegeusis

1. Antennae moniliform (Mexico) P. jiliotupaensis Zaragoza-Caballero, 2008

- Antennae serrate

2. Antennae serrate from antennomere IV to X, body yellowish brown, third antennomere slender, 1.6 times longer than wide (from original illustration) (Ecuador) P. oculatus Wittmer, 1976

- Antennae serrate from antennomere III to antennomere X, third antennomere about as long as wide

3. Eyes protruding, vertex covering $3 / 5$ of head ( $\mathrm{IOW} / \mathrm{OL}=1.45$ ), body infuscate yellow with dark brown head, third antennomere slightly $(1.16 \times)$ longer than wide, tergite IX with rounded apical margin, sternite IX as long as wide, lateral lobes of aedeagus apically broadly rounded (Peru) P. meloi sp. nov.

- Eyes not protruding, vertex covering $3 / 4$ of head ( $\mathrm{IOW} / \mathrm{OL}=2.3$ ), body dark brown, third antennomere slightly $(1.16 \times)$ wider than long, tergite IX with straight apical margin, sternite IX longer than wide, lateral lobes of aedeagusapically narrowly rounded, racket-shaped (French Guiana, Trinidad and Tobago, Venezuela) P. howdeni Wittmer, 1976 


\section{Pseudotelegeusis meloi sp. nov. urn:1sid:zoobank.org:act:60800BF5-532F-4C2E-8BCC-3F0B6A6573E9}

\section{Diagnosis}

Antennae moniliform or serrate, from antennomere III or IV to X. Maxillary palpi 4-segmented, last palpomere enlarged as long as the preceding three together. Labial palpi composed by one palpomere. One tentorial pit, according to former authors (Wittmer 1976b; Ivie 2002; ZaragozaCaballero 2008), but during the present study we observe two distinctly separated tentorial pits on the ventral face of the head capsule of Pseudotelegeusis meloi sp. nov. (Fig. 3B) and P. howdeni Wittmer, 1976 (Fig. 3C).The initial error by Wittmer (1976b), observing only one tentorial orifice, is probably related to the limitations of an optical examination of dry material. His work on the morphological evolution of the tentorium in the Phengodidae family had benefitted either from dissections of the cephalic capsule or from scanning electron microscope examination (Wittmer, 1976a). We used the classical steps of dissecting, clearing in potash solution, mounting in a drop of syrup solution of dimethyl hydantoin formaldehyde and examination with compound microscope in transmitted light at 200-400 $\times$ (see Liberti 2005). In Pseudotelegeusis, we observed that the organization of the tentorium is similar to that of the Phengodidae Distremocephalus texanus (LeConte), as illustrated by Wittmer (1976a: 444, fig. 28). It consists of two arms separate at the base, basally joined by a bridge, distinct and subparallel in their central portion and obliquely curved against the dorsal surface.

\section{Type material}

\section{Holotype}

PERU • 1 गे; "Madre de Dios, CICRA Field station, garden; $12.56940^{\circ} \mathrm{S}, 70.10100^{\circ} \mathrm{W}$; alt. $260 \mathrm{~m}$; 6-16 Sept. 2010; C. Chaboo \& Maria J. Endara leg.; Malaise trap; KUNHM-ENT, PER-10-09MAT-015"; MUSM-ENT.

Paratypes (34 exx.) PERU - Madre de Dios dept. • 1 o ; CICRA Field station, garden; $12.56940^{\circ} \mathrm{S}, 70.10100^{\circ} \mathrm{W}$; alt. 260 m; 6-16 Sep. 2010; Maria J. Endara leg.; Malaise trap; KUNHM-ENT, PER-10-09-MAT-015, KUNHM /SEMC\# 1097969 • 1 万; same location as preceding; 29 Jul.-5 Aug. 2010; PER-10-07MAT-009, former SEMC 1096735; CCo • 1 đ̊; same location as preceding; 26 Aug.-2 Sep. 2010; PER-10-08-MAT-013, KUNHM /SEMC\# 1061709 • 1 đ̊; same location as preceding; 2-9 Sep.2010; PER-10-09-MAT-014; former SEMC 1096363; MUSM-ENT • 1 ô; same location as preceding; 23 Sep.-2 Oct. 2010; PER-10-09-MAT-017, former SEMC 1062359; MUSM-ENT. • 1 đ̄; 12 rd km E Mazuko, p[uen]te. Mazuko; 13²'51.1" S, 70²0'45.9" W, 382m, Malaise trap; 18-22 Aug. 2012; R. R. Cavichiolli. J. A. Rafael, A. P. Santos \& D. M. Takiya leg.; DZUP 458.569. • 2 đう; Tambopata prov., $15 \mathrm{~km}$ NE Puerto Maldonado, Reserva Cusco Amazônica; 12³3' S 6903' W; 200 m; Plot \#Z1U9; 13 Jun. 1989; R.A. Leschen, \#035, Light intercept; MTEC • 1 ô; same location as preceding; Plot \#Z2E8, J.S. Ashe, R.A. Leschen, \#028; KUNHM • $3 \widehat{\partial}^{\lambda}$; same location as preceding; 25 Jun. 1989, J.S. Ashe, R.A. Leschen, \#240, Flight intercept trap; KUNHM 1 § ; same location as preceding; 22 Jun. 1989; J.S. Ashe, R.A. Leschen, \#184, Flight intercept trap; KUNHM • 2 § $\overbrace{}^{\lambda}$; same location as preceding; 28 Jun. 1989; J.S. Ashe, R.A. Leschen, \#308, Flight intercept trap. - Huánuco dept. $\cdot 2 \widehat{\partial}$; provincia de Puerto Inca (150 km ENE of Huanuco), ACP [Area de Conservación Privada y Estación Biologica] Panguana, rio Yuyapichis; $9^{\circ} 36^{\circ} 49^{\prime \prime}$ S, $74^{\circ} 56^{\prime} \mathrm{W}$; alt. $220 \mathrm{~m}$; 1-20 May 2015, Malaise trap, E. Diller leg.; ZSM 2019-11A, ZSM 2019-11B • 1 đ; same data as preceding;

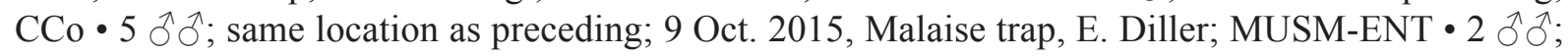
same location as preceding; Lupana weg, Licht Boden [Lupana path, light trap on soil], 6 Oct. 2015, A. Gruppe \& V. Abbt leg.; ZSM 2019-11C, ZSM 2019-11D • 1 \%; same location as preceding, 7 Oct.

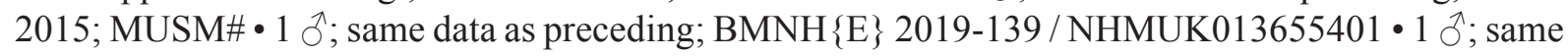


location as preceding; 12 Oct. 2015; CCo 1 § ; same location as preceding, 13 Oct. 2015; BMNH $\{\mathrm{E}\}$

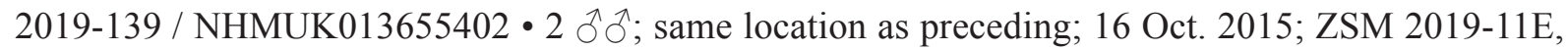
ZSM 2019-11F. - Loreto dept. • 1 § ; provincia de Requena, Jenaro Herrera, on east bank of Ucayali river (about $145 \mathrm{~km} \mathrm{SW}$ of Iquitos and $4 \mathrm{~km}$ E of Jenaro); 4 ${ }^{\circ} 55^{\prime} 0^{\prime \prime} \mathrm{S}, 73^{\circ} 36^{\prime} 49^{\prime \prime} \mathrm{W}$; alt. $135 \mathrm{~m}$; Plot 16, flight interception trap 9 (FIT); forest edge on terra firme; 26 Jul. 2011; G. Lamarre leg.; MUSM-ENT

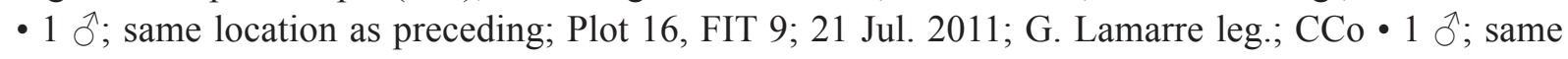
collection data as preceding; Plot 16, FIT 10; 5 Aug. 2011; G. Lamarre leg.; MUSM-ENT.

\section{Diagnosis}

Head light brown, body overall pale yellow. Antennae serrate from antennomere III to X (Figs 1C, 2A). Eyes occupying half of head width, in lateral view. Vertex occupying $3 / 5$ of head in dorsal view (Fig. 1D). Elytron reaching the anterior margin of the third abdominal segment, covering the basal half of the folded hind wings (Figs 1A, 1B, 2A).

\section{Etymology}

The name meloi is given in honor of Gabriel A.R. Melo, a fellow researcher from the Laboratório de Biologia Comparada de Hymenoptera, Universidade Federal do Paraná, Brazil. Gabriel was responsible for receiving us during our visit to UFPR, and for the loan of the first known specimen of this new species.

\section{Description}

\section{Male}

Coloration. Body overall pale yellow, except for brown head.

HEAD. Antennae 11-segmented, serrate from antennomere III to X (Figs 1C, 2A). Eyes dorsally protruding; occupying half of head width, in lateral view. Vertex occupying $3 / 5$ of head in dorsal view (Figs 1D, 2B). Maxillary palpi 4-segmented, last segment as long as first three segments combined length (Fig. 3A). Labial palpi 1-segmented. Two distinct tentorial pits (Fig. 3B). Head slightly wider than long (Fig. 1D), cephalic surface smooth, without distinct punctures.

Thorax. Pronotum transverse (Figs 1E, 2B), 1.4 times as wide as than long. Anterior edge regularly rounded, posterior edge more arched. Lateral edges almost rectilinear. Disc slightly transversally convex, smooth, without distinct punctures, bordered by a furrow and a complete rounded bead except in the median fourth of the anterior and posterior margins. Anterior corners with a deep dimple. Elytron $3.5 \times$ as long as wide (Fig. 1F), reaching the anterior margin of the third abdominal segment (Fig. 1A, 1B). Both elytra dehiscent, narrowing towards the rounded tips. The two basal thirds of the elytral surface shiny, shallowly punctate; apical third of elytra rugulose, with a dense vestiture of brown setae inserted in minute vesicles.

ABdomen. With eight ventrites. Tergite IX transverse, $1.5 \times$ wider than long, apical margin slightly emarginate medially. Tergite X narrow, half-tube shaped (Fig. 2E). Sternite IX cordiform, as long as broad, the apical edge slightly emarginated (Fig. 2F). Aedeagus (Fig. 2D). Phallobase elongate, lateral walls subparallel; apical part of lateral lobes (parameres) laterally straight, their summit roundly truncate; lateral lobes bound on the ventral side by a median styliform blade, prolonged by a gutter guiding the apex of the median lobe; median lobe regularly narrowing from base to apex.

\section{Immatures and females}

Unknown. 


\section{Measurements}

Holotype: TL: $4.6 \mathrm{~mm}$; HW: $0.92 \mathrm{~mm}$; AL: $2.08 \mathrm{~mm}$; IOW: $0.52 \mathrm{~mm}$; OL: $0.38 \mathrm{~mm}$; PL: $0.55 \mathrm{~mm}$; PW: 0.79mm; EL: $1.72 \mathrm{~mm}$; EW: 0.98.

Paratypes from the region of Madre de Dios (9): TL: 3.5-4.5 mm (aver. $4.15 \mathrm{~mm}$ ); AL: 1.76-2.0 mm (aver. $1.86 \mathrm{~mm}$ ); HW: 0.7-0.92 mm (aver. $0.84 \mathrm{~mm}$ ); IOW: 0.39-0.53 mm (aver. 0.49 mm); OL: 0.3-
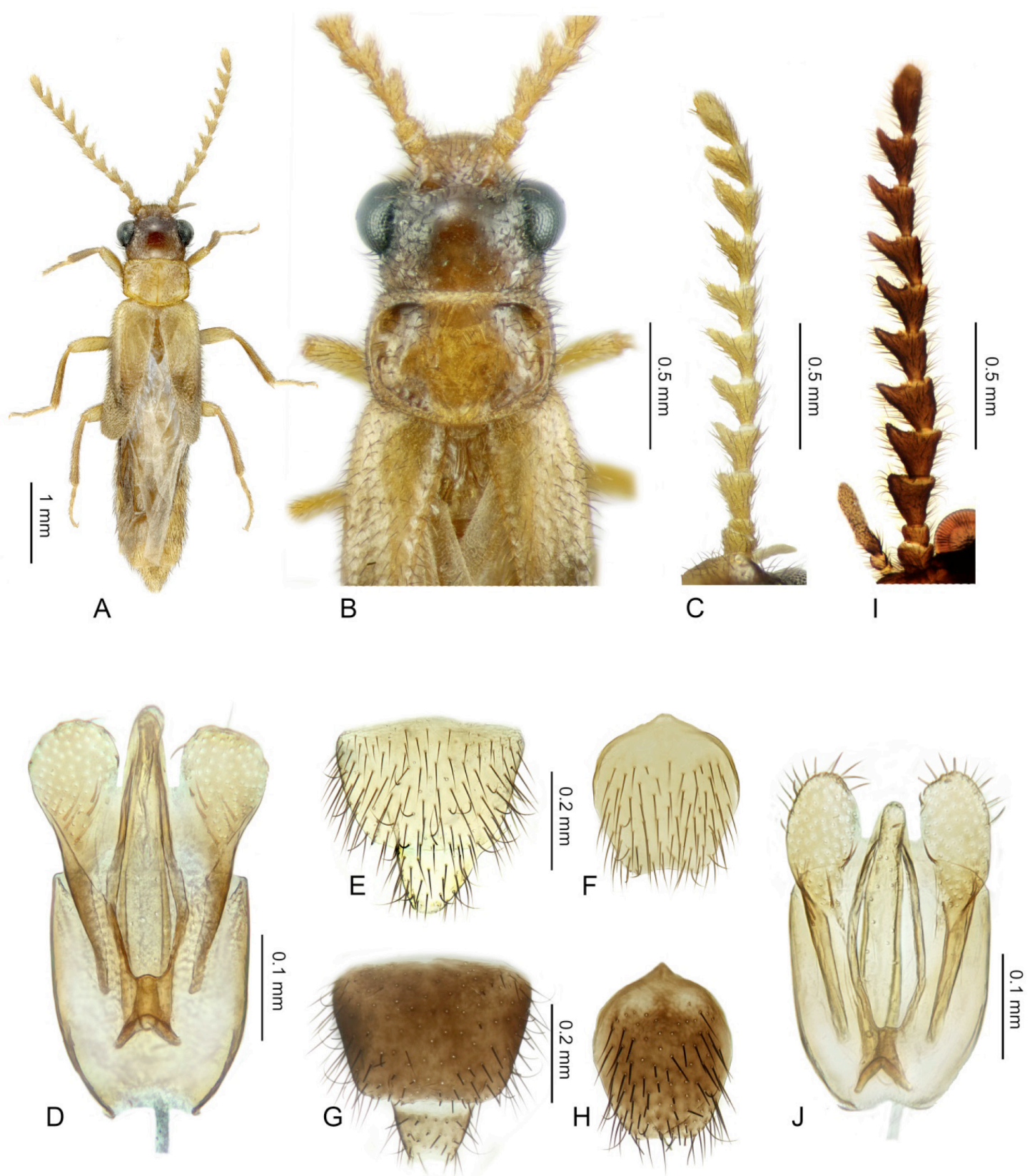

Fig. 2. A-F. Pseudotelegeusis meloi sp. nov., holotype from Madre de Dios, CICRA. A. Habitus. B. Detail of head and pronotum. C. Right antenna. D. Aedeagus, dorsal view. E. Tergites IX-X, dorsal view. F. Sternite IX, ventral view. G-I. Pseudotelegeusis howdeni Wittmer, 1976 specimen from French Guiana. G. Tergites IX-X, dorsal view. H. Sternite IX, ventral view. I. Right antenna. J. Aedeagus, dorsal view. 
$0.37 \mathrm{~mm}$ (aver. $0.33 \mathrm{~mm}$ ); PL: 0.43-0.57 mm (aver. $0.52 \mathrm{~mm}$ ); PW: 0.6-0.78 mm (aver. $0.72 \mathrm{~mm}$ ); EL: 1.42-1.72 mm (aver. $1.56 \mathrm{~mm}$ ); EW: 0.72-0.92 mm (aver. $0.85 \mathrm{~mm}$ ); ratio PW/PL: $1.73-2$ (aver. 1.83).

Paratypes from Huanuco, ACP Panguana (16): TL: $3.2-4.3 \mathrm{~mm}$ (aver. $3.55 \mathrm{~mm}$ ); AL: $1.3-1.78 \mathrm{~mm}$ (aver. $1.55 \mathrm{~mm}$ ); HW: 0.63-0.87 mm (aver. $0.73 \mathrm{~mm}$ ); IOW: 0.38-0.54 mm (aver. $0.47 \mathrm{~mm}$ ); OL: $0.26-$ $0.31 \mathrm{~mm}$ (aver. $0.29 \mathrm{~mm}$ ); PL: 0.41-0.54 mm (aver. $0.48 \mathrm{~mm}$ ); PW: 0.57-0.75 mm (aver. $0.66 \mathrm{~mm}$ ); EL: $1.08-1.48 \mathrm{~mm}$ (aver. $1.26 \mathrm{~mm}$ ); EW: 0.6-0.84 mm (aver. $0.72 \mathrm{~mm}$ ); ratio PW/PL: $1.59-1.952$ (aver. 1.76).

Paratypes from Loreto, Jenaro Herrera (3): TL: 4.2-4.3 mm (aver. $4.23 \mathrm{~mm}$ ); AL: 1.82-1.9 mm (aver. $1.85 \mathrm{~mm}$ ); HW: 0.8-0.9 mm (aver. $0.84 \mathrm{~mm}$ ); IOW: 0.43-0.49 mm (aver. $0.45 \mathrm{~mm}$ ); OL: $0.33-0.37 \mathrm{~mm}$ (aver. $0.35 \mathrm{~mm}$ ); PL: 0.49-0.54 mm (aver. $0.51 \mathrm{~mm}$ ); PW: 0.72-0.79 mm (aver. $0.75 \mathrm{~mm}$ ); EL: $1.42-$ $1.72 \mathrm{~mm}$ (aver. $1.56 \mathrm{~mm}$ ); EW: 0.82-0.86 mm (aver. $0.83 \mathrm{~mm}$ ); ratio PW/PL: 1.76-1.83 (aver. 1.79).

\section{Intra-specific variability}

The general coloration does not show any variability. Paratypes originating from the region of Madre de Dios do not differ significantly from the holotype.

At a distance of $800 \mathrm{~km}$ from the type station, the series of specimens from ACP Panguana (Huanuco) is distinguished by the smaller size and significantly shortened elytra of the specimens, which still remain within the range of variability of the Madre de Dios specimens. All other morphological characters are identical.

At a distance of $1300 \mathrm{~km}$ from the type station, specimens from Jenaro-Herrera (Loreto) differ only in the slightly narrower interocular interval of the vertex, the longer eyes, the pronotum more transverse, the shorter elytra. All the other morphological characteristics, including the aedeagus, ensure its unequivocal specific identity as $P$. meloi sp. nov.

\section{Biology and distribution}

The holotype of Pseudotelegeusis meloi sp. nov. was collected in September, during the beginning of autumn. It inhabits low altitudinal areas of $260 \mathrm{~m}$ in the Peruvian Amazonian Rainforest of Madre de Dios. Paratypes were collected by interception trap, either Malaise traps, or window interception trap. With one series attracted by a UV light trap at the ACP Panguana.

\section{Differential diagnosis}

The new species differs markedly from $P$. jiliotupaensis by the serrate antennae (moniliform in $P$. jiliotupaensis) and the abdomen with eight ventrites (seven in P. jiliotupaensis). Also, this new species differs from P. oculatus by the antennae serrate from antennomeres III to X (from IV to X in P. oculatus) and the convex posterior margin of pronotum (more pointed medially in P. oculatus). The new species most closely resembles $P$. howdeni by their similar antennae, but can be distinguished by the yellowish coloration, the protruding eyes, smaller vertex and the straight anterior margin of pronotum (brown coloration, eyes not protruding, big vertex and the anterior margin of pronotum slightly pointed medially in P. howdeni).

\section{Discussion}

Telegeusinae are among the most enigmatic Elateroid taxa, with unclear phylogenetic affinities and little knowledge gathered about their biology. The subfamily is composed of only three genera and 20 species, over half of which were described based on less than five specimens (Horn 1895; Martin 1931; Barber 1952; Allen \& Huntton 1969; Zaragoza 1975, 1990; Wittmer 1976b; Fleenor \& Taber 2001; 
Zaragoza-Caballero \& Rodríguez-Velez 2011; Zaragoza-Caballero 2008, 2015). So far, no female or larvae were described, and males are rare on most collections. However, the number of specimens in the type series of Telegeusinae descriptions has grown significantly in recent years (Zaragoza-Caballero \& Rodríguez-Velez 2011; Zaragoza-Caballero 2015). The increase of sampled Telegeusids is due to the use of Malaise and Flight Intercept Traps (FITs), which have been proved as effective ways to collect

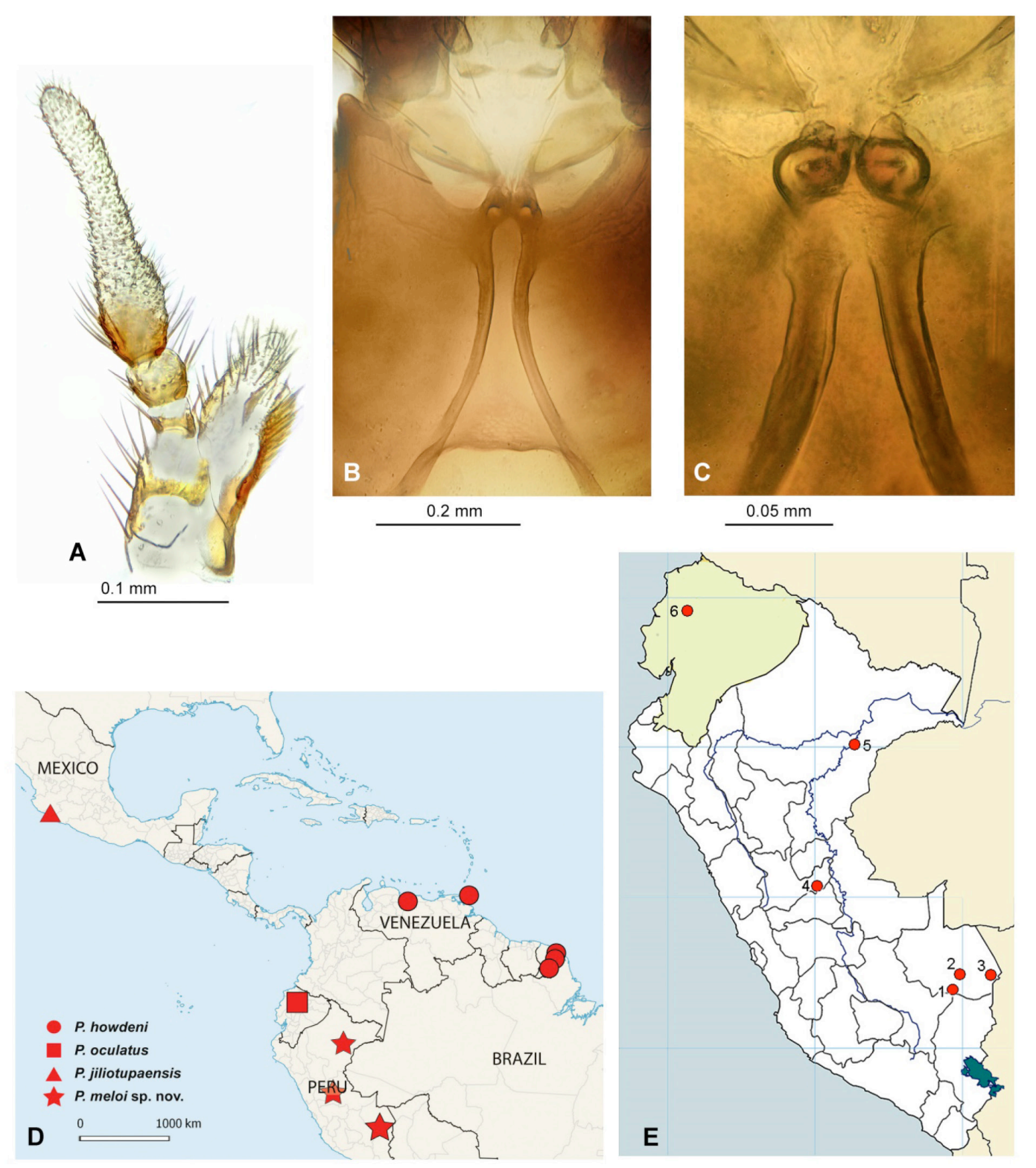

Fig. 3. A. Pseudotelegeusis meloi sp. nov., right maxillar palpi, ventral view. B. Pseudotelegeusis meloi sp. nov., tentorial pits, ventral view. C. Pseudotelegeusis howdeni Wittmer, 1976, tentorial pits, ventral view. D. Distribution map of the genus Pseudotelegeusis Wittmer, 1976. E. Distribution map of Pseudotelegeusis in Ecuador and Peru. Stations 1-5, Pseudotelegeusis meloi sp. nov., from Peru: 1) Madre de Dios, Mazuko; 2) Madre de Dios, CICRA biol. station; 3) Madre de Dios, Puerto Maldonado; 4) Huanuco, Puerto Inca, ACP Panguana; 5) Loreto, Jenaro Herrera. Station 6, Pseudotelegeusis oculatus Wittmer, 1976, from Ecuador: Santo Domingo de los Tsachilas, Rio Palenque biological station. 
these rare beetles. These traps are very successful at collecting small flying insects poorly collected otherwise (Hosking 1979). The description of this new species is evidence of the efficiency these traps in collecting Telegeusid specimens.

The genus Pseudotelegeusis is rather homogenous, both morphologically and geographically, except for $P$. jiliotupaensis. The three South American species, including the one described here, have serrate antennae, the lateral region of the head posterior to eyes with one to one and a half times the eye length, and eight ventrites. Pseudotelegeusis meloi sp. nov. was recorded from the northern Amazon forest but $P$. oculatus was collected by a Malaise trap on the first slope of the western cordillera of Ecuador in a small remaining area of the tropical costal humid forest (Wittmer 1976b). Pseudotelegeusis jiliotupaensis has moniliform antennae, the lateral region of the head posterior to eyes twice the eye length, seven visible ventrites, and is distributed in the deciduous tropical forest in Colima, Mexico (Zaragoza-Caballero 2008). The Mexican species has several characteristics of all three genera of Telegeusinae, and was allocated in Pseudotelegeusis due to the number and morphology of the palpi and the presence of a single tentorial pit (Zaragoza-Caballero 2008). However, a complete taxonomic revision of the genera is needed to ascertain the phylogenetic position of the Mexican species.

The genus distribution includes Mexico, French Guiana, Trinidad and Tobago, Venezuela, Ecuador and Peru (Fig. 3D, 3E). Pseudotelegeusis meloi sp. nov. represents the southernmost record for Telegeusinae, which now occurs from the South of United States to Peru. The large forest areas between the species locations may host further new species, both in South and Central America. New collections, using flight interception traps or Malaise traps, could greatly increase the species richness of the family.

\section{Acknowledgements}

We are very grateful to friends and colleagues of different museums and universities: Juan Grados, Carlos Peña (MUSM, Peru), Angelico Asenjo (UFMT, Brazil), and Gabriel Melo (UFPR, Brazil) for obtaining collecting permits. We thank Rodney R. Cavichiolli (UFPR, Brazil), José A. Rafael (INPA, Brazil), Alan Santos (UNIRIO, Brazil) and Daniela Takyia (UFRJ, Brazil) for collecting the holotype specimen. We thank Gabriel Melo and Norma Ganho (UFPR, Brazil) for providing the loan of the specimen and receiving us during our visit to UFPR. We thank Guilherme Muricy (MNRJ, Brazil) for his valuable revision of the manuscript. We acknowledge Michael Ivie and Vinicius Ferreira for permission to examine the paratypes housed in MTEC and for the assistance during a visit to Montana State University (Bozeman, USA). We are particularly grateful to Caroline Chaboo for the loan of a collection of Telegeusinae made at Centro de Investigación y Capacitación Rio Los Amigos (CICRA research station, Madre de Dios, Peru), preserved in the Kansas University Natural History Museum, Lawrence, USA. We are also grateful to Franz Wachtel who patiently sorted, from alcohol material, the soft Elateroidea collected by Erich Diller at the Panguana Biological Station, Puerto Inca, Huanuco, Peru (Dr Juliana Koepcke de Diller) and preserved at the Zoologische Staatssammlung München, Munich, Germany. Also we acknowledge Greg Lamarre, for the submission of his samplings of Coleoptera made during his doctoral researches at the Centro de Investigaciones, Jenaro Herrera, Loreto, Peru.

\section{Funding}

This work was supported by the Programa de Pós-Graduação em Zoologia do Museu Nacional, Rio de Janeiro [no grant number]. This study was financed in part by the Coordenação de Aperfeiçoamento de Pessoal de Nível Superior - Brasil (CAPES) - Finance Code001, PROTAX CNPQ/CAPES440479/2015-0, CNPq 06105/2016-0, and Faperj /110.040/2014 and 211.522/2016, which allowed us to acquire one of the photographic systems used in this study. 


\section{References}

Allen R.T. \& Hutton R.S. 1969. A new species of Telegeusidae (Leng) from Panama (Coleoptera: Cantharoidea). The Coleopterists Bulletin 23:109-112.

Barber H.S. 1952. Notes on Telegeusis and some relatives (Coleoptera: Lymexylidae). Pan-Pacific Entomologist 28: 163-170.

Bocak L., Motyka M., Bocak M. \& Bocakova M. 2018. Incomplete sclerotization and phylogeny: The phylogenetic classification of Plastocerus (Coleoptera: Elateroidea). PloS one 13 (3): e0194026.

Bocakova M., Bocak L., Hunt T., Teraväinen M. \& Vogler A.P. 2007. Molecular phylogenetics of Elateriformia (Coleoptera): evolution of bioluminescence and neoteny. Cladistics 23 (5): 477-496. https://doi.org/10.1111/j.1096-0031.2007.00164.x

Branham M.A. \& Wenzel J.W. 2001. The evolution of bioluminescence in cantharoids (Coleoptera: Elateroidea). The Florida Entomologist 84(4): 565-586.

Branham M.A. \& Wenzel J.W. 2003. The origin of photic behavior and the evolution of sexual communication in fireflies (Coleoptera: Lampyridae). Cladistics 19 (1): 1-22.

https://doi.org/10.1111/j.1096-0031.2003.tb00404.x

Brooks T.M., Mittermeier R.A., da Fonseca G.A., Gerlach J., Hoffmann M., Lamoreux J.F., Mittermeier C.G., Pilgrim J.D. \& Rodriguez A.S.L. 2006. Global biodiversity conservation priorities. Science 313(5783): 58-61. https://doi.org/10.1126/science.1127609

Cavichioli R.R. \& Takiya D.M. 2012. Four species of the new Amazonian sharpshooter Daedaloscarta gen. nov. (Insecta: Hemiptera: Cicadellidae). Zoologia (Curitiba) 29 (6): 589-597.

Chaparro J.C., Pramuk J.B. \& Gluesenkamp A.G. 2007. A new species of arboreal Rhinella (Anura: Bufonidae) from cloud forest of southeastern Peru. Herpetologica 63 (2): 203-212.

Constantin R. 2010. Les genres de Cantharidae, Lampyridae, Lycidae et Telegeusidae de Guyane française. Contribution à l'étude des coléoptères de Guyane, 2. Le Coléoptériste Supplément au Bulletin de liaison d'ACOREP-France: 32-45.

Data-Fauna-Flora, v5.1. 2017. Logiciel de gestion et d'exploitation des banques de données biogéographiques (freeware). http://zoologie.umons.ac.be/dff/default.asp

Fleenor S.B. \& Taber S.W. 2001. A new long-lipped beetle from Texas and a review of the genus Telegeusis Horn (Coleoptera: Telegeusidae). The Coleopterists Bulletin 55 (4): 481-484.

https://doi.org/10.1649/0010-065X(2001)055[0481:ANLLBF]2.0.CO;2

Goncalves C.C., Takiya D.M. \& Mejdalani G. 2014. Two new species of Platypona DeLong (Hemiptera: Cicadellidae: Iassinae: Gyponini) from Peru and key to the species of the genus. Zootaxa 3811 (3): 359-366.

Horn G.H. 1895. Coleoptera of Baja California. Proceedings of the California Academy of Sciences 5: 225-259.

Hosking G.P. 1979. Trap comparison in the capture of flying Coleoptera. New Zealand Entomologist. 7 (1): 87-92. https://doi.org/10.1080/00779962.1979.9722338

Hunt T., Bergsten J., Levkanicova Z., Papadopoulou A., John O.S., Wild R., Hammond P.M., Ahrens D., Balke M., Caterino M.S., Gómez-Zurita J., Ribera I., Barraclough T.G., Bocakova M., Bocak L. \& Vogler A.P. 2007. A comprehensive phylogeny of beetles reveals the evolutionary origins of a superradiation. Science 318 (5858): 1913-1916. https://doi.org/10.1126/science.1146954 
Ivie M.A. 2002. The transfer of Pseudokarumia Pic from Dascillidae (Karumiinae) to Telegeusidae, with a key to world genera of Telegusidae. The Coleopterists Bulletin 56 (4): 582-584.

Kundrata R., Bocakova M., \& Bocak L. 2014. The comprehensive phylogeny of the superfamily Elateroidea (Coleoptera: Elateriformia). Molecular Phylogenetics and Evolution 76: 162-171.

Liberti G. 2005. Improved solutions of two water-soluble media for mounting beetle genitalia. The Coleopterist 14 (1): 29-35.

Martin J.O. 1931. A new Telegeusis from Arizona (Coleoptera). Pan-Pacific Entomologist 8: 91-92.

Mckenna D.D., Wild A.L., Kanda K., Bellamy C.L., Beutel R.G., Caterino M.S., Farnum C.W., Hwaks D.C., Ivie M.A., Jameson M.L., Leschen R.A., Marvaldi A.E., McHugh J.V., Newton A.F., Robertson J.A., Thayer M.K., Whiting M.F., Lawrence J.F., Slipinski A., Maddison D.R. \& Farrell B.D. 2015. The beetle tree of life reveals that Coleoptera survived end-Permian mass extinction to diversify during the Cretaceous terrestrial revolution. Systematic Entomology 40 (4): 835-880.

https://doi.org/10.1111/syen.12132

Oliveira P.J., Asner G.P., Knapp D.E., Almeyda A., Galván-Gildemeister R., Keene S., Raybin R.F. \& Smith R.C. 2007. Land-use allocation protects the Peruvian Amazon. Science 317 (5842): 1233-1236. https://doi.org/10.1126/science.1146324

Portal Oficial del Gobierno Regional de Madre de Dios. 2015. Madre de Dios, Peru: Gobierno Regional de Madre de Dios.Available from: http://regionmadrededios.gob.pe/new/ [accessed 2018 Apr. 2017].

QGIS Development Team. 2016. A free and open source Geographic Information System. Available from: http://www.qgis.org/en/site/index.html [accessed 2018 Apr. 2017]

Roza A.S., Quintino H.Y.S., Mermudes J.R.M. \& da Silveira L.F.L. 2017. Akamboja gen. nov., a new genus of railroad-worm beetle endemic to the Atlantic Rainforest, with five new species (Coleoptera: Phengodidae, Mastinocerinae). Zootaxa 4306 (4): 501-523. https://doi.org/10.11646/zootaxa.4306.4.3

Servicio Nacional de Áreas Naturales Protegidas por el Estado (SERNANP). 2018. Peru: Ministerio del Ambiente. Available from: http://www.sernanp.gob.pe/bahuaja-sonene [accessed 2018 Apr. 2017]

Wittmer W. 1976a. Arbeitenzueiner Revision der Familie Phengodidae (Coleoptera). Entomologische Arbeitenausdem Museum Frey 27: 415-524.

Wittmer W. 1976b. Eineneue Gattung der Familie Telegeusidae (Col.). Mittelungen der Schweizerischen Entomologischen Gesellschaft. Bulletinde la Société Entomologique Suisse 49: 293-296.

Zaragoza S. 1975. Una nueva especie de Telegeusis Horn (Coleoptera: Telegeusidae) de Chamela, Jalisco, México. Anales Instituto de Biologia. Universidad Nacional Autonoma de México, Serie Zoología 46 (1): 63-68.

Zaragoza S. 1990. Una especie nueva de Telegeusis Horn, 1985 (Coleoptera: Telegeusidae) de Nueva León, México. Universidad Nacional Autónoma de México, Serie Zoología 61 (2): 307-312.

Zaragoza-Caballero S. 2008. Nueva especie de Pseudotelegeusis (Coleoptera: Telegeusidae) del estado de Colima, México. Revista mexicana de biodiversidad 79 (2): 369-372.

Zaragoza-Caballero S. 2015. Nuevos telegeúsidos (Coleoptera: Telegeusidae) de Hidalgo, México. Dugesiana 22(2): 179-186.

Zaragoza-Caballero S. \& Rodriguez-Velez B. 2011. Five new species of Telegeusis Horn, 1895 (Coleoptera: Telegeusidae) from Mexico, with a key to the species. Zootaxa 2917 (1): 59-68. 
Manuscript received: 2 August 2018

Manuscript accepted: 17 June 2019

Published on: 26 November 2019

Topic editor: Gavin Broad

Desk editor: Marianne Salaün

Printed versions of all papers are also deposited in the libraries of the institutes that are members of the EJT consortium: Muséum national d'Histoire naturelle, Paris, France; Botanic Garden Meise, Belgium; Royal Museum for Central Africa, Tervuren, Belgium; Royal Belgian Institute of Natural Sciences, Brussels, Belgium; Natural History Museum of Denmark, Copenhagen, Denmark; Naturalis Biodiversity Center, Leiden, the Netherlands; Museo Nacional de Ciencias Naturales-CSIC, Madrid, Spain; Real Jardín Botánico de Madrid CSIC, Spain; Zoological Research Museum Alexander Koenig, Bonn, Germany; National Museum, Prague, Czech Republic. 